\title{
CHOMSKY E CIÊNCIAS COGNITIVAS
}

\author{
Sonia Maria Lazzarini Cyrino
}

UEL

As ciências cognitivas, estudando a inteligência e os sistemas inteligentes, englobam diferentes disciplinas, como: a psicologia (experimental e cognitiva), inteligência artificial, lingüística, filosofia, neurociências, antropologia, economia e psicologia social. Assim, segundo Simon \& Kaplan (1993), há muitos métodos diferentes, muitas abordagens conceituais diferentes e muitas arquiteturas diferentes para o sistema inteligente dentro da pesquisa das ciências cognitivas.

De maneira geral, as ciências cognitivas preocupamse com "inteligência", ou "habilidade para executar tarefas independentemente da natureza do sistema físico que exibe essa habilidade" (Simon \& Kaplan, 1993, p. 2, minha tradução). Assim, segundo esses autores, as ciências cognitivas: 1) constróem uma teoria abstrata de processos inteligentes, sem preocupação sobre o sistema físico ou biológico; 2) estudam a inteligência humana (ou animal) para formar uma teoria sobre processos inteligentes desses organismos; 3) estudam a "inteligência do computador" para extrair princípios computacionais que subjazem à organização e comportamento de programas, nesse caso, inteligentes. A meta seria construir um modelo computacional da mente.

Duas maneiras de construir esse modelo são enfocadas atualmente: a abordagem simbólica e a abordagem conexionista. A primeira, que surge da lógica matemática, propõe que os elementos desse modelo são símbolos (modelo simbólico), tendo aí dois enfoques (raciocínio - pensamento como um processo de inferência, e busca heurística pensamento como um processo de solução de problemas e formação de conceitos). A segunda, que tem ligações com a

Signum: Estud. Ling., Londrina, n. 2, 155-167, out. 99 
neurofisiologia, possui como elementos "neurônios esquematizados", interconectados em uma rede (modelo conexionista). A orientação também é computacional, mas as representações não são simbólicas.

Dupuis (1995, p. 74) afirma que essas duas maneiras, ou modelos, seriam, na realidade, dois paradigmas das ciências cognitivas. O primeiro assume que "pensar é calcular como um computador, ou seja, sobre símbolos que têm ao mesmo tempo uma realidade material e um valor semântico de representação". O segundo assume que pensar é calcular, de maneira paralela, os comportamentos surgindo das interações entre os elementos simples que compõem a rede.

Assim, para Dupuis, nas ciências cognitivas, "conhecer é simular", pois pretende-se modelizar, ou seja, reproduzir o funcionamento da mente, no computador. No caso da simulação simbólica, os símbolos são manipulados de maneira a proporcionar um modelo da performance cognitiva que envolve o raciocínio lógico (é baseado nas regras da lógica). $\mathrm{Na}$ simulação conexionista, as redes são treinadas, aprendendo com base nas regularidades que encontram, de maneira a proporcionar um modelo de reconhecimento de padrões e categorização.

A lingüística contribui com as ciências cognitivas na medida em que considera a linguagem como espelho da mente. Chomsky, expoente dessa visão, desenvolve uma teoria que pressupõe uma capacidade humana inata para a linguagem.

Para aprofundar a idéia da linguagem como espelho da mente, é preciso estabelecer, como fazem Simon \& Kaplan (1993), se a capacidade inata para a linguagem é uma faculdade distinta, ou se é parte da capacidade cognitiva humana em geral. Certamente, a linguagem não tem uma semântica única e em separado, ou seja, há um componente semântico comum, que vários sistemas (e.g. linguagem, visão) compartilham. Entra aí a questão da "língua do pensamento" (language of thought, Fodor, 1975; Pinker, 1994): a idéia de 
que pensamentos têm conteúdos e, portanto, têm propriedades semânticas: o pensamento é articulado em mentalês, uma língua interna, diferente de qualquer língua em particular, mas tendo propriedades da linguagem, na qual as computações cognitivas ocorrem ${ }^{1}$. Há vários argumentos para tanto: assim como a linguagem, o pensamento denota e atribui; o raciocínio segue a inferência formal, que é baseado na condição de verdade das sentenças. $O$ principal argumento a favor do mentalês é que o pensamento é sistemático (o pensamento tem propriedades composicionais como a semântica: para qualquer sentença de uma língua há expressões relacionadas sistematicamente, que também são sentenças da língua; qualquer sistema cognitivo que pode compreender uma sentença como: João ama Maria, pode também entender a sentença sistematicamente relacionada Maria ama João) e produtivo (sentenças adicionais podem ser acrescentadas ao corpus de uma língua, assim como não há limite para o pensamento) (ver também language of thought, em Guttenplan, $1994{ }^{2}$ ).

\footnotetext{
Em lingüistica, a teoria da representaçāo semântica pretende proporcionar uma teoria que caracterize o que "pegamos" no processamento de uma sentença. As afirmaçōes empiricas especificas sobre a natureza da representação semântica são (Chierchia \& McConnell-Ginet, 1990, p. 329): a) Ela tem um núcleo booleano (pode-se isolar conectores lógicos como $e, o u, n a ̄ o$, que constituem os instrumentos centrais para juntar os pedaços de informação); b) ela incorpora uma categorização de objetos semânticos: individuos, propriedades, e proposições, relacionados de um certo modo, e com uma certa estrutura; c) ela tem instrumentos para expressar a quantificação, usando ou não mecanismos de ligação de variáveis; d) ela inclui expressōes indexicais e outros aspectos sensiveis a contextos. Essa teoria, no entanto, não faz nenhuma afirmação sobre os processos psicológicos específicos que formam os mecanismos reais de compreensão. O cálculo lógico é a base do modo como o significado é representado mentalmente pois tal cálculo está encaixado no mundo e, acredita-se, as representações mentais representam a realidade.

${ }^{2} \mathrm{O}$ modelo simbólico, mas não o conexionista, dá conta dessas duas propriedades do pensamento. As arquiteturas conexionistas não empregam a composicionalidade em suas representaçōes.
}

Signum: Estud. Ling., Londrina, n. 2, 155-167, out. 99 
Sem argumentar especificamente a favor do mentalês, Chomsky, no entanto, propõe que a lingüística pode dar sua contribuição para o estudo da mente. Nesse sentido, a importância do trabalho de Chomsky para a lingüística e as ciências cognitivas somente pode ser apreciada em nossos dias se comparada aos estudos lingüisticos anteriores.

Os estruturalistas encaravam o estudo da linguagem como sendo um colecionar de dados e análise descritiva desses dados. Nos anos 50, principalmente, o objetivo era desenvolver procedimentos objetivos ("discovery procedures") para classificar corpora de enunciações. Chomsky, porém, argumenta que a lingüística deve se preocupar com a construção de teorias e não simplesmente com a metodologia. A linguagem, ou seja, a possibilidade de formar sentenças, é infinita no ser humano. Não seria possível, a partir de dados, descobrir os procedimentos classificatórios de uma língua - isto é, somente esses procedimentos não demonstram a capacidade infinita de se gerar sentenças. A lingüística deveria se preocupar em escrever gramáticas que incorporassem essa propriedade.

Daí o interesse de Chomsky em formalismos matemáticos, desenvolvendo uma hierarquia de tipos de gramática, e mostrando quais tipos de seqüências cada tipo de gramática poderia ou não poderia gerar. Em seu primeiro livro, Syntactic Structures (1957), Chomsky tinha o objetivo de motivar a teoria lingüística e sua formalização através de gramáticas gerativas que deveriam estar sujeitas a certas condições de adequação. $\mathrm{O}$ objetivo era demonstrar que somente um tipo específico de gramática gerativa obtinha todos os níveis de adequação: uma gramática gerativa que, além de regras de estrutura sintagmática (phrase structure rules) possuísse regras transformacionais. Nessa época, existiam dois modelos de gramática gerativa: finite state grammars $\mathrm{e}$ phrase structure grammars. O primeiro era semelhante a um modelo promovido pelos teóricos das comunicações 
(Newmeyer, 1986). O segundo tipo de gramática gerativa teria como resultado os mesmos tipos de descrições que os procedimentos estruturalistas produziam. Assim, Chomsky teve que demonstrar as inadequações de tais modelos em seu livro. Era dirigido àqueles (poucos) que se interessavam na construção de uma teoria lingüística formal não empiricista.

Chomsky mostra que os modelos existentes eram inadequados pois línguas naturais exibem construções que estariam além da capacidade gerativa desses modelos gerativos.

Nessa fase, a ênfase era em gerar o conjunto correto de seqüências para uma língua natural. $\mathrm{O}$ significado estaria fora do estudo lingüístico, sendo que considerações psicológicas não teriam qualquer papel na teorização sintática. Já nos anos 60, a chamada Teoria Padrão (a partir de Aspects of the Theory of Syntax, 1965) coloca um componente semântico e já indagava como o conhecimento da linguagem está representado na mente. Nessa época, a teoria propõe dois níveis de representação lingüística: a estrutura profunda e a estrutura superficial. A primeira servia como base para a interpretação semântica, e a segunda como base para a interpretação fonológica. As tranformações mapeavam um nível de representação ao outro.

O período seguinte foi marcado por uma luta por tentar se restringir o poder das transformações, pois a teoria padrão era tão rica em poder descritivo que sua habilidade para propor análises de construções particulares começaram a perder no nível da adequação explanatória: uma teoria deveria ter "adequação explanatória" se proporcionar meios de inferir uma gramática tendo como base fatos da língua relacionado com learnability ("aprendizibilidade"). O fato mais notável sobre a linguagem, segundo Chomsky, é a distância que existe entre o corpus pequeno arbitrário e incompleto a que uma criança tem acesso e a capacidade ilimitada das pessoas para produzir e compreender sentenças. Argumento da "pobreza do estímulo" - indica a capacidade inata do ser 
humano para a linguagem: uma pequena amostra da língua em questão dá à criança informação suficiente para que se adquira a língua, a partir de princípios universais (Gramática Universal).

Nos anos 80, o modelo GB ("Government-Binding") procura reduzir as gramáticas de línguas particulares a fixações de número pequeno de parâmetros relacionados a princípios universais. Em linhas gerais, para Chomsky, o estudo da linguagem é parte de um projeto mais geral: mapear em detalhes a estrutura da mente (ver Language and Nature, onde suas idéias sobre o assunto estão mais explícitas).

A "revolução chomskyana" teve influência em outras áreas fora da lingüística. Se a exata forma da teoria gramatical não poderia ter sido de interesse para um não-lingüista, que contribuição as idéias de Chomsky trouxeram?

Newmeyer (1986) afirma que a teoria apresentada já em Syntactic Structures atraiu a atenção e imaginação de numerosos estudiosos e até pedagogos pois pareciam apresentar soluções para problemas em todas as áreas onde a linguagem tem um papel importante. Chomsky mesmo não pretendeu apresentar as implicações psicológicas de seu modelo, embora pessoas que resenharam sua obra tenham apontado essas implicações. Lees (1957), por exemplo, ataca a teoria indutiva de aprendizagem, tomando por base a idéia de que se a gramática que o lingüista constrói é formada por princípios abstratos não poderia ser aprendida indutivamente pelo falante. Segundo ele, as noções de aprendizagem da época deveriam ser revisadas.

Newmeyer ainda afirma que a resenha de Verbal Behavior de Skinner feita por Chomsky, levou à compreensão de que sua teoria de linguagem era muito mais do que a simples manipulação de símbolos, mas sim um modelo psicológico de um aspecto do conhecimento humano. Essa resenha apresenta a refutação básica da psicologia behaviorista ao tomar cada construto básico do behaviorismo e demonstrar que ou ele leva a falsas predições ou simplesmente não tem conteúdo: 
"Uma resenha crítica de seu livro deve mostrar que... com uma leitura literal (onde os termos do sistema descritivo tenham algo como os significados técnicos dados nas definições de Skinner) o livro cobre quase nenhum aspecto do comportamento lingüistico, e que com uma leitura metafórica, não é mais científico do que enfoques tradicionais a este assunto, e raramente tão claro e cuidadoso" (Chomsky, 1959:31, apud Newmeyer, 1986, minha tradução)

Chomsky ainda escreveu que

"A real habilidade observada de um falante em distinguir sentenças de não-sentenças, detectar ambigüidades, etc. aparentemente nos força a chegar à conclusão de que essa gramática é de um caráter extremamente complexo e abstrato, e que a criancinha teve sucesso em empreender o que, de um ponto de vista formal, pelo menos, parece ser um tipo notável de construção de teoria" (p. 57, minha tradução)

e argumenta que

"o fato de que todas as crianças normais adquirem gramáticas essencialmente comparáveis e de grande complexidade com um rapidez notável sugere que os seres humanos são de alguma forma projetados para isso, com manipulação de dados ou habilidade de 'formação de hipóteses' de um tipo e complexidade desconhecidos" (p. 57, minha tradução)

A teoria desenvolvida por Chomsky, no entanto, é diferente dos pressupostos de Piaget, para quem a linguagem

Signum: Estud. Ling., Londrina, n. 2, 155-167, out. 99 
é construída em cima de abstrações a partir de um esquema sensório-motor. O célebre debate Piaget-Chomsky deixa isso claro (ver Piatelli-Palmarini, 1994).

Newmeyer ainda aponta para o impacto do trabalho de Chomsky para áreas como a filosofia da ciência:

'De fato, o livro de Israel Scheffler's, The Anatomy of Inquiry (1963), um clássico na filosofia da ciência, citou os resultados de Chomsky em Syntactic Structures para apoiar sua posição por uma análise não-empiricista da investigação científica. Ele mostrou que, já que Chomsky demonstrou a necessidade de definir tais noções teóricas como 'substantivo' e 'morfema' independentemente de línguas particulares, então os filósofos deveriam se preocupar com a natureza geral das leis científicas, em vez de ter um enfoque empiricista atomístico" (Newmeyer, 1986, p. 53, minha tradução)

Mais recentemenete, Chomsky (1993, 1994, 1995) apresenta suas idéias sobre linguagem, pensamento e seu fundamento biológico. O estado atual, segundo Chomsky, é que temos boas teorias sobre alguns aspectos da linguagem e da mente, mas somente idéias rudimentares sobre a relação disso com sua base biológica, ou seja, o cérebro. Como outros sistemas complexos, o cérebro humano pode ser visto como uma matriz de subcomponentes que interagem, o que pode ser estudado em vários níveis: átomos, células, conjuntos de células, redes neurais, sistemas computacionais-representacionais, etc. Não sabemos qual desses enfoques vai trazer uma melhor compreensão. Porém, em vários domínios, incluindo a linguagem, os enfoques computacionais-representacionais trazem afirmações mais fortes com estatuto científico. Por exemplo, estudos computacionais-representacionais (lingüística) dão razões fortes para se acreditar que as expressões lingüísticas estão em 
certas categorias de "boa-formação": ou são bem-formadas, ou estão em violação a várias condições sobre sistemas de regras que foram descobertos. Estudos recentes da atividade elétrica do cérebro encontrou repostas distintas a várias dessas categorias de expressões. Esses estudos relacionam dois níveis de pesquisa: atividade elétrica do cérebro, e sistemas computacionais-representacionais. No caso, as teorias computacionais-representacionais têm mais suporte empírico, e são melhores no poder explanatório pois a relevância dos estudos da atividade elétrica do cérebro está na correlação com as teorias computacionais-representacionais que têm maior abrangência e são mais ricas. As várias categorias de expressão têm um lugar e são explicadas por princípios que se aplicam não somente a elas. Sem essas teorias, os resultados dos estudos elétricos não teriam uma explicação, pois não há teorias sobre a atividade elétrica do cérebro - nenhuma razão conhecida para que se encontrem esses resultados e não outros.

Assim, Chomsky coloca a questão da possibilidade de se relacionarem análises lingüísticas em termos de computação simbólica com propostas advindas das neurociências. Para Chomsky, como vimos, a teoria lingüística estaria "na frente" com relação às neurociências. Para que a unificação seja possível, é preciso esperar até que essas ciências desenvolvam novos meios de teorizar.

Com efeito, Schnelle (1996a) mostra que as descobertas e teorias propostas pela neurobiologia de uma certa forma vêm de encontro a teorias lingüísticas já avançadas. Esses resultados mostram que não é provável que palavras e sintagmas isolados estejam estritamente localizados no cérebro - uma palavra tem vários aspectos: fonético, fonológico, morfológico, sintático e semântico, e seria razoável supor que esses diferentes aspectos seriam representados e processados em partes diferentes do cérebro (ver também Pinker, 1994, p. 315-316). Palavras pertencentes a partes do discurso diferentes estariam, da mesma forma, distantes umas 
das outras, assim como diferentes significados de um mesmo "lemmata". Vários resultados de pesquisa empírica, como "PET scans", mostram que verbos estariam na área lateral frontal e substantivos na área temporal. Além disso, partículas que determinam direção e locação, flexões e palavras dêiticas, isto é categorias funcionais, estariam representadas em outras áreas do cérebro, mais próximas das áreas onde as representações de configuração e locação corporais estão localizadas, ou seja, na área parietal inferior.

Esses fatos explicariam por que o preenchimento de posições da estrutura argumental e a determinação de seus papéis não são prejudicados quando há uma lesão na parte inferior do córtex parietal. Nesse caso, somente morfemas flexionais e palavras de classe fechada são eliminadas, isto é, categorias gramaticais. Assim, Schnelle argumenta que o córtex parietal inferior, embora seja essencial na organização sintática mais complexa, não estaria envolvido em simples estruturas argumentais, as quais seriam padrōes sintáticos simples que não exigem uma compreensão configuracional.

Além disso, dados provenientes de desordens da fala (Caplan, 1992; Pinker, 1994) mostram que alguns afásicos não conseguem produzir verbos, flexões e palavras funcionais, outros não conseguem usar sufixos flexionais, mas não têm problemas com os sufixos derivacionais. Alguns têm problemas para reconhecer palavras faladas, outros produzem a fala, mas sem sentido. Embora não tenha sido possivel precisar a exata localização de cada componente lingüístico, algumas desordens encontradas podem ser explicadas por uma teoria lingüística. A diferença entre categorias lexicais e funcionais seria uma dessas explicações já proposta na teoria.

No entanto Schnelle (1996b) apresenta suas idéias de como a questão da unificação pode ser enfocada. Para o autor, é possível traduzir sistemas formais da lingüística, definidos simbolicamente, como por exemplo, estruturas de constituintes, para sistemas equacionais de modo que as 
estruturas para as expressões emergem como um conjunto de suas possíveis soluções. $\mathrm{O}$ autor procura traduzir o formalismo da teoria lingüística para padrões de ativação de redes neurais. Para isso, as representações formais da lingüística deveriam ser transformadas em representações notacionalmente diferentes cuja interpretação neuronal seria direta. Para o autor, que afirma discordar de Chomsky sobre a questão da unificação, a lingüística também deveria mudar essencialmente seu modo de teorizar para refletir o efeito das redes neurais. Assim, para o autor, a questão da unificação estaria em se tentar correlacionar teorias computacionais da mente com teorias computacionais do cérebro.

Porém, embora Schnelle (1996b) queira mostrar que a unificação desse modo estaria mais próxima, podemos ver que sua proposta não é um passo nesse sentido, e sim somente mais uma idéia ("rudimentar", como diria Chomsky, cf. acima) de como relacionar teorias lingüísticas com sua base biológica.

Outras tais idéias (talvez menos rudimentares), porém, têm sido avançadas. Pinker (1994 e 1997) apresenta uma teoria computacional da mente para explicar a linguagem e o pensamento, que pretende ser apenas isso, isto é, uma teoria sobre o possível relacionamento de teorias lingüisticas e sua base biológica. A proposta não pretende resolver o problema da unificação pois o autor reconhece a ignorância atual acerca da ação real nos padrões de conexão entre neurônios: na realidade, "virtualmente nada é conhecido acerca do funcionamento dos microcircuitos do cérebro humano, pois há falta de voluntários que desejem doar seus cérebros à ciência antes que estejam mortos" (Pinker, 1997, p. 184, minha tradução).

Pinker também se utiliza de redes neurais, mas afirma que, embora o conexionismo pretenda simular a atividade mental tendo o cérebro como análogo, as redes conexionistas não são modelos realistas do cérebro. Além disso, argumenta que as redes neurais sozinhas não podem explicar a 
complexidade da linguagem e do pensamento humano. É a estruturação das redes em programas para manipular símbolos que podem dar essa explicação. A crítica de Pinker ao conexionismo puro (ou "conectoplasma", como o chama) centra-se na observação de que, por si mesma, uma rede com uma camada oculta é uma implementação "high-tech" da velha doutrina de aprendizagem por associação de idéias e generalização por semelhança. Pinker enfatiza que a manipulação de símbolos subjaz à linguagem humana, e mostra como tal proposta pode ser implementada em Pinker (1997), exemplificando em Pinker (1994) com a formação do passado dos verbos em inglês. Dessa forma implementa a proposta chomskiana de a linguagem estar biologicamente codificada no cérebro humano.

Referências bibliográficas

CAPLAN, D. Language: structure, processing and disorders. Cambridge, Mass : MIT Press, 1992.

CHOMSKY, N. Syntactic Structures. The Hague : Mouton, 1957.

. Resenha de B.F. Skinner, Vebal Behavior. Language 35:26-57, 1959.

MIT Press, 1965. Aspects of the Theory of Syntax. Cambridge, MA : Language and thought. London : Moyer Bell, 1993. . In: Guttenplan, S. (Org.) A Companion to the philosophy of mind. Cambridge : Blackwell, 1994. . "Language and nature" Mind 104:1-61, 1995.

LEES, R. B. Review of Noam Chomsky, Syntactic Structures. Language 29:113-127, 1957.

NEWMEYER, F.J. Linguistic Theory in America. 2. ed. Boston : Academic Press, 1986.

PIATELLI-PALMARINI, M. "Ever since language and learning: afterthoughts on the Piaget-Chomsky debate" Cognition 50:315-346, 1994. 
PINKER, S. The language instinct. New York : Harper Collins, 1994.

How the mind works. New York : W W Norton and Co, 1997.

SCHNELLE, H. "Approaches to computational theories of language. A review of recent proposals" Theoretical Linguistics 22 (1/2): 49-104, 1996a.

"Reflections on and Chomsky's 'Language and thought'" Theoretical Linguistics 22 (1/2): 104-124, $1996 \mathrm{~b}$.

Signum: Estud. Ling., Londrina, n. 2, 155-167, out. 99 